\title{
The immune response against oryzatensin increase VEGF and MMP-9 experssion in HEP-G2 cell line
}

\begin{abstract}
Background: Previous studies introduced ORZ for pharmacological purposes. As ORZ reduces NKs originated IFN- $\gamma$ potentially. Therefore this study was designed to evaluate VEGF and MMP-9 expression in HEP-G2 cell line after culture with the soup of ORZ treated PBMCs.

Materials and methods: In current in-vitro study, PBMCs from seven healthy male subjects (aged 20 to 30 years) were isolated by ficoll density gradient. The soup of ORZ treated PBMCs were cultured with HEP-G2 cell line and the VEGF and MMP-9 expression in the cancerous cell line were measured by real time PCR.

Results: VEGF and MMP-9 expression increased after 48 hours, but only the increment of MMP-9 expression was statistically significant $(\mathrm{P}<0.05)$. The expression of these genes did not alter significantly after $24 \mathrm{~h}$ and $72 \mathrm{~h}$ incubation of the cancer cells with the soup of ORZ treated PBMCs soup $(\mathrm{P}>0.05)$.

Conclusion: By considering the increase of MMP-9 and VEGF expression in the cancerous cell line cultured with ORZ-stimulated PBMCs soup, it seems long term administration of ORZ, as a drug, may change the response of immune system toward carcinogenesis.
\end{abstract}

Keywords: oryzatensin, bioactive peptide, immune system, cell proliferation, oryza
Volume 5 Issue 3 - 2017

\author{
Meisam Barati,' Mehdi Yousefi, ${ }^{2}$ Hamed \\ Mohammdi, ${ }^{2}$ Mehrangiz Ebrahimi \\ Mameghani ${ }^{3}$ \\ Student Research Committee, School of Nutrition and Food \\ Science, Tabriz University of Medical Sciences, Iran \\ ${ }^{2}$ Department of Immunology, Faculty of Medicine, Tabriz \\ University of Medical Sciences, Iran \\ ${ }^{3}$ Nutrition Research Center, Department of Community \\ Nutrition, School of Nutrition, Tabriz University of Medical \\ Sciences, Iran
}

Correspondence: Meisam Barati, Nutrition Research Center, Department of Community Nutrition, School of Nutrition, Tabriz University of Medical Sciences, Attar Neishaboori St. Golgasht Ave, Tabriz, Iran, Tel 989-141-005-68I, Fax 984-I3337I-97I, Email msbrtir@gmail.com

Received: November 29, 2016 | Published: March 23, 2017
Abbreviations: ORZ, oryzatensin; MMP-9, matrix metalloproteinase 9; PBMCs, peripheral blood mononuclear cell; VEGF, vascular endothelial growth factor; NKs, natural killer cells, $\mathrm{PCR}$, polymerase chain reaction

\section{Introduction}

ORZ (amino acid sequence: Gly-Tyr-Pro-Met-Tyr-Pro-Leu-ProArg) is a digestion resistant peptide elicited from brown rice (molecular weight=1093.3). The brown rice bio-active peptide illustrate various functions such as Polymorphonuclear cells stimulation, activation of $\mathrm{C} 3 \mathrm{a}$ (one of the complement system components) receptor $(\mathrm{C} 3 \mathrm{aR})$ and the ileum contraction. ${ }^{1,2} \mathrm{ORZ}$ activates $\mathrm{C} 3 \mathrm{aR}$ and imitates $\mathrm{C} 3 \mathrm{a}$ function. The ORZ modification was firstly performed to produce a digestion resistant peptide with enhanced affinity to C3aR. Oral administration of modified ORZ, through the digestive system, induces a number of relatively important functions such as antiamnesic, anorexigenic and anti-analgesic ones. ${ }^{3,4}$

Peripheral blood mono-nuclear cells (PBMCs) contain natural killer cells (NKs), T lymphocytes, B lymphocytes and monocytes. NKs bind to C3a and C5a by C3aR. ${ }^{5}$ Activation of C3aR on NKs reduces NKs originated interferon $\gamma($ IFN- $\gamma)$, ${ }^{5,6}$ IFN- $\gamma$ has been shown to have a pivotal role in $\mathrm{T}_{\text {helperl }} / \mathrm{T}_{\text {helper }}(\mathrm{Th} 1 / \mathrm{Th} 2)$ skewing. Therefore, IFN- $\gamma$ reduction makes the condition in favor of Th 2 activation. ${ }^{7,8} \mathrm{Th} 1$ with IFN- $\gamma$ together can induce apoptosis in cancer cells. ${ }^{9}$ Vascular Endothelial Growth Factor (VEGF) is a regulator of angiogenesis during different conditions such as embryogenesis, tumorigenesis, etc. Matrix Metalloproteinase 9 (MMP-9) belongs to MMPs that also have role in angiogenesis by destruction of extra-cellular matrix. Both VEGF and the MMPs have role in progression of cancer. ${ }^{10,11}$ As studies assessing the effects of immune response versus food component on cancer progression is rare, this study was designed to investigate the effects of immune response against ORZ, as a food component, on cancer progression In-vitro.

\section{Material and methods}

\section{PBMCs Isolation, MTT assay and co-culture}

Seven healthy male volunteers aged 20-30 years were recruited in the current study which approved by the Ethic Committee of Tabriz University of Medical Sciences and written informed consent was obtained from each subject. In this study, all tests on human participants were in accordance with the ethical standards of the institutional committee as well as the 1964 Helsinki declaration and its later amendments (Ethics code: Tbzmed.rec-1393-3250). Blood samples were collected in heparinized tubes and diluted with RPMI1640 containing antibiotics (Gibco, UK). Then PBMCs were obtained by centrifuging the blood samples on Ficoll-Hypaque and washed by RPMI-1640 containing antibiotic and finally, the pellet was suspended in RPMI-1640 containing 10\% FBS (Gibco, USA) and the viability was assessed by Trypan blue staining. ORZ with $98.8 \%$ purity (Biomatic, USA) was purchased from Biomatic Corporation. The $4 \times 106$ PBMCs were cultured in exposed with ORZ (the final ORZ concentration was 10-5 M). The PBMCs were cultured without ORZ, as control. The media of both groups were separated from PBMCs after 72 hours incubation. HEP-G2 cell line was purchased from Pasteur Institute of Iran. In order to culture of HEP-G2 cells with the soup of ORZ stimulated PBMCs, $5 \times 105$ HEP-G2 cells were seeded in $25 \mathrm{~mm}$ flask and after $24 \mathrm{~h}$ of incubation, the cancerous cells were washed with PBS. HEP-G2 cells were cultured in the Isolated PBMCs soup from both treatment and control groups in the ratio of $1: 1(5 \mathrm{ml}$ PBMCs soup $+5 \mathrm{ml}$ fresh medium). After $24 \mathrm{~h}, 48 \mathrm{~h}$ and $72 \mathrm{~h}$ incubation of cancerous cells with the PBMCs soup, the medium was removed then the cells were stored at $-70^{\circ} \mathrm{C}$ until RNA extraction.

\section{RNA extraction cDNA synthesis and Real- time PCR}

Total RNA was extracted from Hep-G2 cells at $24 \mathrm{~h}, 48 \mathrm{~h}$ and $72 \mathrm{~h}$ 
after incubation using Thermo Scientific Gene JET RNA Purification Kit (K0731) according to the manufacturer's instruction. Extracted RNA was dissolved in nuclease-free water. RNA purification was assessed by NanoDrop Spectrophotometers. The integrity of RNA samples were assessed using 1\% standard agarose gel. Reverse transcription was carried out using the RevertAidTM first strand cDNA synthesis kit (K1622; Fermentas, Germany). Two $\mu \mathrm{g}$ RNA was used for the first-strand cDNA synthesis in a total volume of $20 \mu \mathrm{L}$ according to the manufacturer's guidelines. All PCRs were done using the Corbett Rotor-Gene ${ }^{\mathrm{TM}} 6000$ HRM (Corbett Research, Australia) in a total volume of $20 \mu \mathrm{L}$ containing Power SYBR Green master mix (2x) (TaKaRa Ex Taq HS, Japan), Primer, cDNA plus nuclease free water. The mRNA-specific primers were designed using Oligo 7 v.7.52 software (Molecular Biology Insights, Inc, USA). The sequences are listed in (Table 1). Each $\beta$-actin, MMP-9 and VEGF amplification were performed in triplicates for each sample. Delta CT values were calculated in relation to $\beta$-actin $\mathrm{CT}$ values by the $2^{-\Delta \Delta \mathrm{CT}}$ method, in which $\Delta \mathrm{CT}$ represents the difference between the CT value of target genes and the $\mathrm{CT}$ value of $\beta$-actin.

Table I The Primers Sequences

\begin{tabular}{lll}
\hline Genes & & Sequence $\left(\mathbf{5}^{\prime} \rightarrow \mathbf{3}\right.$ ') \\
\hline \multirow{2}{*}{ B-actin } & Reverse & GTAGTTTCGTGGATGCCACA \\
& forward & TCCCTGGAGAAGAGCTACG \\
VEGF & Reverse & GTGGGTGGGTGTGTCTACAGGAA \\
& forward & CGCCACCACACCATCACCATC \\
MMP-9 & Reverse & ATCCGGCAAACTGGCTCCTTC \\
& forward & ATTTCTGCCAGGACCGCTTCTAC \\
\hline
\end{tabular}

\section{Statistical analysis}

The data analysis was performed by SPSS software ver.21.0 The Kolmogrov-Sirnov test was used to assess the distribution of quantitative variables. One Sample $\mathrm{T}$ test was done for intragroups statistical analysis. P-values less than 0.05 were considered statistically significant.

\section{Results}

MMP-9 and VEGF expression were assessed in HEP-G2 cell line at $24 \mathrm{~h}, 48 \mathrm{~h}$ and $72 \mathrm{~h}$ after incubation with soup of ORZ-stimulatedPBMCs. VEGF fold changes in first, second and third time points were $1.21 \pm 0.31,1.45 \pm 0.38$, and $1.25 \pm 0.23$, respectively. In the alltime points the expression of VEGF increased but the increments were not statistically significant in comparison with the control groups $(\mathrm{P}>0.05)$. The expression of MMP-9, similar to VEGF, increased in the cancerous cells compared with control groups after the treatment. The over-expressions of MMP-9 in HEP-G2 at 24h and $72 \mathrm{~h}$ after incubation were not statistically significant $(\mathrm{P}>0.05)$ while the treatment significantly increased MMP-9 expression after $48 \mathrm{~h}$ incubation of HEP-G2 cell line with the soup of ORZ-treated PBMCs $(\mathrm{P}<0.05)$ (Figure 1-3).

\section{Discussion}

In the current study, we demonstrated that immune response against ORZ increase cancer progression In-vitro. ORZ like C3a can bind to $\mathrm{C} 3 \mathrm{aR}$ and activate it. ${ }^{1,2}$ Receptor of $\mathrm{C} 3 \mathrm{a}$ is a $\mathrm{G}$ protein coupled receptor and that have role in the complement system. Recently it has been accepted that PMNs express C3aR. NKs comprise about $15 \%$ of PBMCs. ${ }^{12,13}$ Min et al. in an In-vitro study revealed that NKs express $\mathrm{C} 3 \mathrm{aR}$ to detect $\mathrm{C} 3 \mathrm{a}$ and $\mathrm{C} 5 \mathrm{a}$. Also the authors demonstrated that $\mathrm{C} 3 \mathrm{a}$ reduce INF- $\gamma$ production by NKs. ${ }^{6,14-16}$ Cellular immune response is induced by Thl cells. Cancer patients have impaired cell mediated immunity. The impairment is associated with Thl to Th2 skewing. Th1 differentiation is dependent mainly to IFN- $\gamma$. IFN- $\gamma$ promotes the CD4+ naïve T lymphocytes to differentiate toward the Th1 and inhibits the differentiation of Th2. Some mutations in the receptors of IFN- $\gamma$ increase cancer risk. ${ }^{17-19}$

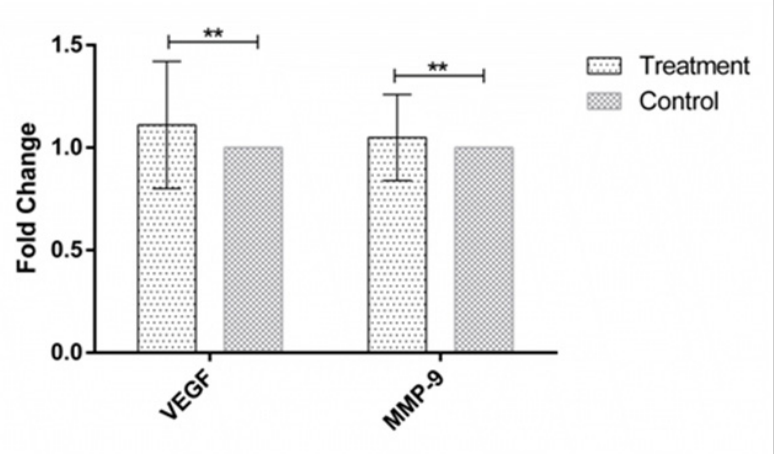

Figure I The expression ofVEGF and MMP-9 in human Hep-G2 cell line after $24 \mathrm{~h}$ incubation with the soup of ORZ exposed PBMCs. $X$-axis represents the genes and $Y$-axis shows fold change of the genes. Statistical analysis was done by One Sample T test. Each point represent the mean \pm SD. $* * P>0.05$. VEGF: Vascular Endothelial Growth Factor. MMP-9: Matrix Metalloproteinase 9.

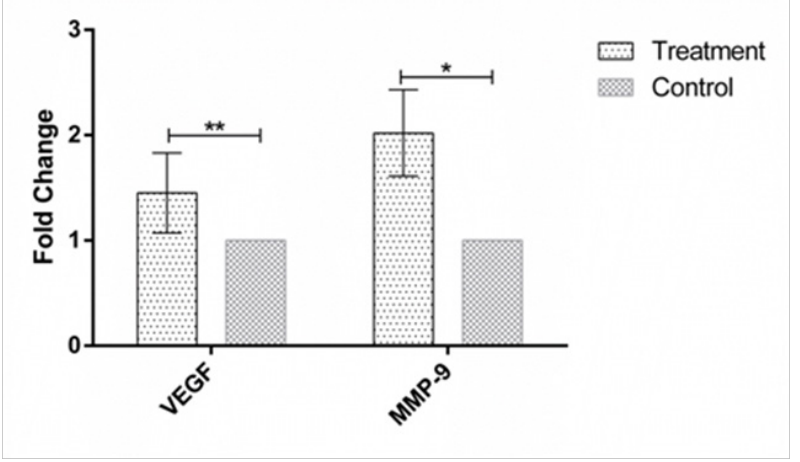

Figure 2 The expression ofVEGF and MMP-9 in human Hep-G2 cell line after $48 \mathrm{~h}$ incubation with the soup of ORZ exposed PBMCs. $X$-axis represents the genes and $Y$-axis shows fold change of the genes. Statistical analysis was done by One Sample T test. Each point represent the mean \pm SD. $* * P>0.05$. $* P<0.05$. VEGF:Vascular Endothelial Growth Factor. MMP-9: Matrix Metalloproteinase 9.

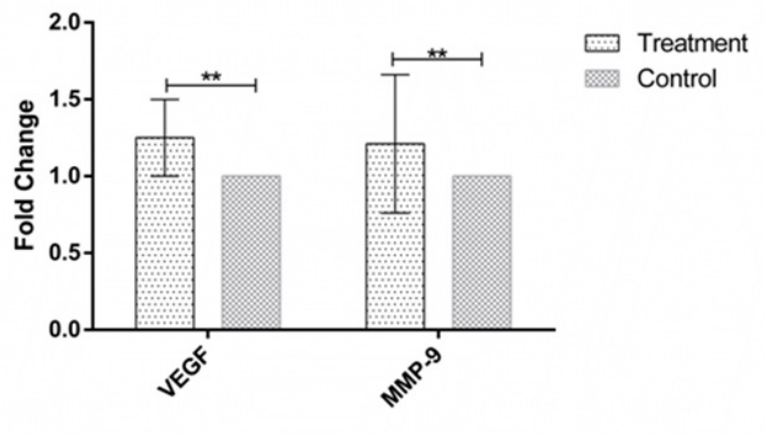

Figure 3 The expression ofVEGF and MMP-9 in human Hep-G2 cell line after $72 \mathrm{~h}$ incubation with the soup of ORZ exposed PBMCs. $\mathrm{X}$-axis represents the genes and Y-axis shows fold change of the genes. Statistical analysis was done by One Sample T test. Each point represent the mean \pm SD. **P $>0.05$. VEGF: Vascular Endothelial Growth Factor. MMP-9: Matrix Metalloproteinase 9. 
The over expression of MMP-9 and VEGF in cancer cells were seen in this study. Assessing the expression of mentioned genes in HEP-G2 cells after culture with the soup of ORZ stimulated PBMCs in this study proposed that the immune response versus ORZ may be Th2 based response in people aged 20-30 years. Th cells play a critical role in the immune system responses regulation. These cells based on the cytokines production subdivide to Th1 or Th2. ${ }^{20,21}$ Th1 based response increases IFN- $\gamma$ production which in turn has direct effect on the proliferation of Th1. However it showed inverse effect on the proliferation of Th2. ${ }^{6,22,23} \mathrm{Th} 1$ lymphocytes and IFN- $\gamma$, involve in anticancer mechanisms whereas $\mathrm{Th} 2$ response boost cancerous cells proliferation. ${ }^{9,24}$ VEGF plays critical role in the angiogenesis of tumor. Therefore, inhibition of VEGF action leads to the suppression of tumor growth. The function of VEGF in cancer progression is not limited to angiogenesis. MMP-9 strongly associated with tumors metastasis. ${ }^{10,25-27}$

The current study has some limitations. Subjects aged 20 to 30 years old individuals were recruited in the study and other age groups were not evaluated. Responses of immune system change during lifespan. ${ }^{28,29}$ In the other hand more experiments (i.e. ELISA and Flow cytometry) are necessary to confirm this conclusion.

\section{Conclusion}

By considering the increase of MMP-9 and VEGF expression in the cancerous cell line cultured with the soup of ORZ-stimulated PBMCs, it appeared that long term administration of ORZ, as a drug, may change the response of immune system and possibly could sensitize target populations to cancer.

\section{Acknowledgments}

The authors thank Tabriz University of Medical Sciences. This work was supported by Tabriz University of Medical Sciences.

\section{Conflicts of interest}

The authors declare no conflicts of interest.

\section{Ethical issues}

Not applicable.

\section{References}

1. Takahashi M, Moriguchi S, Ikeno M, et al. Studies on the ileumcontracting mechanisms and identification as a complement C3a receptor agonist of oryzatensin, a bioactive peptide derived from rice albumin. Peptides. 1996;17(1):5-12.

2. Takahashi $\mathrm{M}$, Moriguchi $\mathrm{S}$, Yoshikawa $\mathrm{M}$, et al. Isolation and characterization of oryzatensin:a novel bioactive peptide with ileumcontracting and immunomodulating activities derived from rice albumin. Biochem Mol Biol Int. 1994;33(6):1151-1158.

3. Jinsmaa Y, Takenaka Y, Yoshikawa M. Designing of an orally active complement $\mathrm{C} 3 \mathrm{a}$ agonist peptide with anti-analgesic and anti-amnesic activity. Peptides. 2001;22(1):25-32.

4. Ohinata K, Suetsugu K, Fujiwara Y, et al. Suppression of food intake by a complement C3a agonist [Trp 5]-oryzatensin (5-9). Peptides. 2007;28(3):602-606.

5. Kojima M, Wakai K, Tamakoshi K, et al. Diet and colorectal cancer mortality:results from the Japan Collaborative Cohort Study. Nutr Cancer. 2004;50(1):23-32.

6. Min X, Liu C, Wei $\mathrm{Y}$, et al. Expression and regulation of complement receptors by human natural killer cells. Immunobiology. 2014;219(9):671-679.
7. Raziuddin S, al-Dalaan A, Bahabri S, et al. Divergent cytokine production profile in Behcet's disease. Altered Th1/Th2 cell cytokine pattern. J Rheumatol. 1998;25(2):329-333.

8. Theofilopoulos AN, Koundouris S, Kono DH, et al. The role of IFNgamma in systemic lupus erythematosus:a challenge to the Th1/Th2 paradigm in autoimmunity. Arthritis Res. 2001;3(3):136-141.

9. Braumuller H, Wieder T, Brenner E, et al. T-helper-1-cell cytokines drive cancer into senescence. Nature. 2013;494(7437):361-365.

10. Egeblad M, Werb Z. New functions for the matrix metalloproteinases in cancer progression. Nature Reviews Cancer. 2002;2(3):161-174.

11. Wang D, Wang $\mathrm{H}$, Guo $\mathrm{Y}$, et al. Crosstalk between peroxisome proliferator-activated receptor $\delta$ and VEGF stimulates cancer progression. Proceedings of the National Academy of Sciences. 2006;103(50):19069-19074.

12. Ducruet AF, Hassid BG, Mack WJ, et al. C3a receptor modulation of granulocyte infiltration after murine focal cerebral ischemia is reperfusion dependent. Journal of Cerebral Blood Flow \& Metabolism. 2008;28(5):1048-1058.

13. Yuan Y, Adams SD, Dinauer DM, et al. 98-P:KIR mRNA Expression in PBMC and Enriched NK Cells Assayed by Quantitative Real-Time PCR. Hum Immunol. 2013;119.

14. Constant SL. B lymphocytes as antigen-presenting cells for CD4+ T cell priming in vivo. J Immunol. 1999;162(10):5695-5703.

15. Evans DE, Munks MW, Purkerson JM, et al. Resting B lymphocytes as APC for naive T lymphocytes:dependence on CD40 ligand/CD40. $J$ Immunol. 2000;164(2):688-697.

16. Kidd P. Th1/Th2 balance:the hypothesis, its limitations, and implications for health and disease. Altern Med Rev. 2003;8(3):223-246.

17. Abbas AK, Lichtman AH, Pillai S. Cellular and molecular immunology: Elsevier Health Sciences. 2014.

18. Wang L, Wang Y, Song Z, et al. Deficiency of interferon-gamma or its receptor promotes colorectal cancer development. $J$ Interferon Cytokine Res. 2015;35(4):273-280.

19. García-Tuñón I, Ricote M, Ruiz A, et al. Influence of IFN-gamma and its receptors in human breast cancer. BMC Cancer. 2007;7:158.

20. Saxena R, Kaur J. Th1/Th2 cytokines and their genotypes as predictors of hepatitis B virus related hepatocellular carcinoma. World J Hepatol. 2015;7(11):1572-1580.

21. Hong M, Jiang Z, Zhou YF. Effects of thermotherapy on Th1/Th2 cells in esophageal cancer patients treated with radiotherapy. Asian Pac J Cancer Prev. 2014;15(5):2359-2362.

22. Reiche EM, Nunes SO, Morimoto HK. Stress, depression, the immune system, and cancer. Lancet Oncol. 2004;5(10):617-625.

23. Mostafazadeh A, Saravi M, Niaki HA, et al. HLA-DR1, Circulating Th1/Th2 Cytokines and Immunological Homunculus in Coronary Atherosclerosis. Iran J Allergy Asthma Immunol. 2011;10(1):11-19.

24. Protti MP, De Monte L. Cross-talk within the tumor microenvironment mediates Th2-type inflammation in pancreatic cancer. Oncoimmunology. 2012;1(1):89-91.

25. Chekhonin VP, Shein SA, Korchagina AA, et al. VEGF in tumor progression and targeted therapy. Curr Cancer Drug Targets. 2013;13(4):423-443.

26. Nishida N, Yano H, Nishida T, et al. Angiogenesis in cancer. Vascular health and risk management. 2006;2(3):213-219.

27. Gialeli C, Theocharis AD, Karamanos NK. Roles of matrix metalloproteinases in cancer progression and their pharmacological targeting. FEBS J. 2011;278(1):16-27. 
28. $\mathrm{Wu} \mathrm{D}$, Meydani SN. Age-associated changes in immune and inflammatory responses:impact of vitamin E intervention. J Leukocyte Biol. 2008;84(4):900-914.
29. Yuan M, Kiertscher SM, Cheng Q, et al. Delta 9-Tetrahydrocannabinol regulates Th1/Th2 cytokine balance in activated human T cells. $J$ Neuroimmunol. 2002;133(1-2):124-131. 